\title{
O SUS sobreviverá aos tempos de pandemia?
}

\author{
Will SUS survive pandemic times?
}

\author{
Carlos Octavio Ocké-Reis'
}

DOI: 10.1590/0103-11042020E417

\section{Introdução}

DE ACORDO COM OCKÉ-REIS 1,2, A ORGANIZAC̣ÃO MUNDIAL DA SAÚDE (OMS) elevou a Covid19, infecção respiratória aguda provocada pelo novo coronavírus (SARS-CoV2), à categoria de pandemia no dia 11 de março de 2020, cuja disseminação vem afetando a vida social e econômica dos países em escala global. Apesar da insegurança sobre a magnitude e a duração desta pandemia, um conjunto de países adotou medidas para fortalecer suas economias, suas redes de proteção social e seus sistemas de saúde. Vários bancos centrais reduziram os juros e defenderam políticas fiscais expansionistas, exigindo ações para proteger o mercado de trabalho, ampliar a licença médica dos trabalhadores, oferecer moratória do pagamento de dívidas e hipotecas etc.

No Brasil, desde o anúncio da pandemia pela OMS, o Ministério da Economia não deveria ter permanecido prisioneiro da estratégia de restringir os investimentos públicos e gastos sociais, de negar o papel do Banco Nacional de Desenvolvimento Econômico e Social (BNDES) como garantidor do crédito de longo prazo da economia, enfim, de manter veladamente a política de austeridade fiscal, como hoje fica claro com o atraso da execução dos recursos aprovados para o combate da Covid-19.

Essa postura fiscalista é irresponsável. Dadas a recessão da economia brasileira e a necessidade de controlar a epidemia, o governo deveria ter rompido com a política de austeridade fiscal para retomar o crescimento econômico, aumentar a arrecadação e fortalecer as políticas sociais no contexto do aumento da pobreza, da desigualdade e do desemprego na sociedade brasileira.

Na verdade, os investimentos e as despesas deveriam ser avaliados pela sua eficácia e efetividade, isto é, pelo efeito multiplicador na economia, e não apenas pelos efeitos sobre o deficit primário ${ }^{\mathbf{1} 2}$. Além da adoção das medidas preconizadas pela OMS, mudar a política econômica e fortalecer o Sistema Único de Saúde (SUS) são as alternativas mais seguras para proteger a população brasileira contra o coronavírus.

\section{Pandemia e crise}

1 Instituto de Pesquisa

Econômica Aplicada (Ipea) - Rio de Janeiro (RJ), Brasil. carlos.ocke@ipea.gov.br
Para o relatório do Fundo Monetário Internacional (FMI) divulgado em abril deste ano, essa crise será certamente maior do que a do crash de 1929. A exemplo de outros países, o governo precisa sustentar a demanda e garantir a renda do conjunto da população, bem como o abastecimento de alimentos, de remédios e de produtos de primeira necessidade, mantendo as cadeias de produção e de distribuição em funcionamento e coordenando o sistema financeiro a partir do planejamento entre Estado e sociedade. 
No entanto ${ }^{3}$,

[...] apesar das iniciativas aprovadas pelo Congresso Nacional no contexto do decreto de calamidade pública, sob a batuta do capital financeiro, o governo produz o seguinte círculo vicioso: de um lado, ataca o distanciamento social devido à queda da atividade econômica. De outro, apesar da flexibilização das regras fiscais, aplica uma política econômica tímida, deixando de liberar recursos suficientes para estados e municípios, para pequenas e médias empresas, bem como para os trabalhadores formais, informais e desempregados. Dessa maneira, ao não irrigar liquidez na economia na proporção exigida pela crise, ao não distribuir renda nem garantir empregos, Bolsonaro joga a maioria da população contra tal distanciamento, uma vez que esta não possui meios materiais para sustentar sua vida cotidiana.

Estamos diante de uma complexa crise político-institucional. Tudo leva a crer que, sob o governo Bolsonaro, não haverá saída democrática para a superação das crises sanitária e econômica. A captura do Ministério da Saúde pelos militares e a política de austeridade dificultam a construção de um acordo nacional, que permita aos estados e municípios colaborarem no controle da doença. Pior: em boa parte precarizados, não estão garantidas as condições salariais e de trabalho seguras para os profissionais de saúde nem serão adotadas medidas rigorosas para proteger as classes populares e os grupos vulneráveis.

Para Silva e Ocké-Reis ${ }^{4}$,

[...] a democratização da saúde, promovida pela Constituição de 1988, representou verdadeiro avanço do processo civilizatório. Em plena epidemia, não devemos abrir mão desse direito social, sob pena de colocar em risco a vida de milhares de brasileiros para sustentar uma política de austeridade fiscal danosa, que se encontra sob fogo cruzado nas principais economias do mundo, inclusive pelos que a defendiam como única alternativa até bem pouco tempo atrás.
A pandemia da Covid-19 tem sido emblemática para a saúde do Brasil ${ }^{5}$. Antes dela, o SUS ocupava protagonismo na agenda política às avessas do debate atual. Os arautos do liberalismo diziam que o SUS não cabia no Estado e defendiam o teto de gasto como expresso na âncora fiscal presente na proposta de orçamento a ser enviada ao Congresso Nacional.

\section{Governo Bolsonaro}

Ora, para Ocké-Reis ${ }^{6}$

[...] se Bolsonaro não prioriza o combate à COVID-19, não protege a economia popular, não cuida dos profissionais de saúde e não salva vidas, por que o campo democrático, popular e socialista continua vacilante na luta pela sua derrubada? Defender o impeachment de um governo tutelado pelos militares, apesar de farta base jurídica, exigirá a construção de uma sólida unidade política contra a extrema-direita e unidade programática contra o neoliberalismo.

Deve-se mobilizar a sociedade, pressionar os centros de decisão política e chamar a atenção da comunidade internacional, vivificando as redes sociais como esfera pública digital, corolário de uma nova democracia participativa. Esse é o caminho dos democratas que são contra um governo que coloca a vida de cidadãos em risco.

De modo análogo ao que foi feito na elaboração da última Constituição ${ }^{6}$,

[...] o bloco histórico sanitarista deve ter o compromisso de contribuir para recompor as forças democráticas, reconstruir as alianças partidárias e elaborar um programa econômico alternativo em defesa da vida, da democracia e do SUS, pautado pela solidariedade e pela ética pública, devolvendo a esperança de meIhores dias aos brasileiros. Na prática, o governo acaba sabotando as medidas emergenciais para controlar a epidemia e tratar a doença como proposto pelo Conselho Nacional de Saúde, 
pelos gestores estaduais e municipais de saúde e pelo movimento da reforma sanitária brasileira. Bolsonaro torna, portanto, a resistência oferecida ao seu projeto despótico em uma luta de Sísifo, penalizando os que estão na linha de frente do combate à COVID-19. Essa vontade consciente possui preponderância decisiva neste período histórico. O governo Bolsonaro não reúne mais condições políticas e éticas para governar o Brasil. As mortes provocadas pelo novo coronavírus pesam sobre seus ombros com a cumplicidade dos militares, os quais aparelharam o Ministério da Saúde, promovendo um vexame internacional, que fere o decoro presidencial e desrespeita o luto da nação.

\section{O SUS sobreviverá?}

Qualquer avaliação neste momento deve partir do subfinanciamento crônico do SUS. Segundo a OMS, em 2015, o gasto público em saúde no Brasil em relação ao Produto Interno Bruto (PIB) foi tão somente de $3,8 \%$, enquanto, por exemplo, na Coreia do Sul responde por 4,2\%, seguida de Chile e Argentina (4,9\%), Espanha (6,5\%) e Itália (6,7\%). O National Health Service (NHS) britânico (similar ao nosso SUS) gasta 7,9\% do PIB.

Dessa maneira, o Brasil precisa se preparar para conviver com a Covid-19. O custeio para os investimentos da sua fase aguda e os agravos decorrentes da doença sobrecarregarão o governo federal, bem como estados e municípios, que devem cobrir, no futuro, a demanda reprimida de cirurgias eletivas, exames diagnósticos e terapêuticos, além de consultas a especialistas, que estão suspensas neste momento. Além do mais, no contexto dos desafios impostos por doenças transmissíveis, tais como dengue, sarampo e influenza, o estresse causado pelo coronavírus se sobrepõe às necessidades relativas às doenças do aparelho circulatório, às neoplasias e às causas externas.
$\mathrm{Na}$ verdade, embora a Emenda Constitucional (EC) 106 tenha suspendido os requisitos fiscais da Lei de Diretrizes Orçamentárias, da Lei de Responsabilidade Fiscal e da Regra de Ouro, a Emenda tem o propósito de manter inalteradas as regras fiscais após o decreto de calamidade pública. Com isso, por exemplo, o congelamento do piso determinado pela EC 95, que retirou $\mathrm{R} \$ 22,5$ bilhões do SUS entre 2018 e 2020, continuará vigente depois da pandemia7.

Deveríamos ter em mente a necessidade de dinheiro novo para atender a população no período seguinte à fase exponencial da epidemia, que vai exigir mais recursos diante do aumento do desemprego, da queda da renda e da expulsão da clientela da medicina privada. Dobrar a aposta na política de (hiper)austeridade fiscal é um erro. David Stuckler e Sanjay Basu deram contribuição importante nesse sentido. No livro, publicado em 2013, intitulado 'The body economic. Why austerity kills'8, os autores criticaram os efeitos das políticas de austeridade sobre as condições de saúde das populações.

De modo que, para enfrentar o novo coronavírus, a partir da introdução do decreto de calamidade pública e da EC 106, o governo flexibilizou temporariamente o regime fiscal contracionista, financiando os gastos por meio de endividamento, agora permitido pela suspensão da regra de ouro, e pelo uso dos recursos desvinculados da Conta Única do Tesouro. Apesar da ampliação da dotação autorizada do orçamento, vale assinalar a lentidão do governo na execução dos recursos da pandemia, em especial, na área de saúde, pois, até início de setembro, apenas cerca de $70 \%$ dos valores haviam sido pagos ${ }^{9}$.

Mostra-se necessário, portanto, mudar o piso federal da saúde em 2021, medida plenamente justificável, dada a gravidade da emergência sanitária provocada pelo coronavírus, que amedronta países e desafia a ciência, cujas incertezas merecem toda a atenção das autoridades governamentais. 


\section{Medidas de combate ao novo coronavírus}

Os efeitos da crise sanitária de 2020 demandarão recursos adicionais para o financiamento das ações e dos serviços públicos de saúde. Contudo, será preciso alterar também a diretriz estabelecida para o piso federal do SUS no Projeto de Lei de Diretrizes Orçamentárias no ano de 2021. É oportuno alertar que o piso constitucional constitui referência de aplicação mínima, portanto, não proíbe destinar recursos adicionais para $o$ atendimento das necessidades de saúde da população, em particular no ano subsequente ao da crise da Covid-19, que provavelmente persistirá nos próximos anos, mesmo com a vacina e com os medicamentos disponíveis.

Tendo-se em mente os espaços abertos com o Decreto de Calamidade Pública e pela EC 106, as seguintes medidas devem ser adotadas agora e no futuro ${ }^{10}$ :

i) Aplicação imediata de recursos adicionais no SUS, que poderiam ser financiados com a venda de títulos públicos, emissão de moeda e/ou utilização de parte do superavit financeiro da Conta Única do Tesouro Nacional, criando um fundo público no valor mínimo de $\mathrm{R} \$ 22,5$ bilhões (perda apurada nos exercícios de 2018, 2019 e 2020 em decorrência da mudança da regra do piso do SUS federal pela Emenda Constitucional 95/2016).

ii) Suspensão de todos os atos que mudaram o financiamento da política de saúde, particularmente aqueles referentes à Portaria $\mathrm{n}^{\circ}$ 2.979/2019 do Ministério da Saúde - que instituiu o novo modelo de financiamento da atenção primária à saúde e extinguiu o Piso de Atenção Básica (PAB) fixo, que garantia, aos municípios, o acesso a recursos regulares e automáticos segundo o critério populacional.

iii) Aprovação da Contribuição sobre Grandes Fortunas no parlamento, substituindo o dispositivo constitucional que criou o Imposto sobre Grandes Fortunas. Os recursos seriam repartidos entre União, estados e municípios e vinculados às áreas da saúde, ciência e tecnologia, saneamento básico, segurança alimentar e assistência social. Além do mais, conforme o art. 150 da Constituição Federal, esta contribuição poderá ser cobrada no próprio ano da aprovação. Será calculada a partir de uma alíquota percentual progressiva sobre valores acima de $\mathrm{R} \$ 10$ milhões registrados na declaração de bens e patrimônios do imposto de renda sobre pessoa física e jurídica.

iv) Tramitação da PEC 01-D/2016 para aprovação em segundo turno na Câmara dos Deputados e em dois turnos no Senado Federal, ampliando o piso federal da saúde para 19,4\% da Receita Corrente Líquida, a ser atingido de forma escalonada em sete anos contados a partir do primeiro ano de vigência.

v) Resposta, com urgência, das Ações Diretas de Inconstitucionalidade (ADI), que tratam da redução dos pisos federais da saúde, provocada pela EC 86/2015 e pela EC 95/2016, em tramitação no Supremo Tribunal Federal.

vi) Retomada dos investimentos da área de ciência, tecnologia e inovação, que ganhou força a partir dos anos 2000. Houve iniciativas importantes, visando reduzir a dependência externa na área da saúde, a partir de linhas de financiamento no BNDES, no Ministério da Saúde e no Ministério de Ciência e Tecnologia. Essa política de substituição de importação procurou desenvolver a produção de bens essenciais e estratégicos, o que poderia capacitar o País, hoje, a atuar com protagonismo no combate à pandemia.

\section{Considerações finais}

Em meio à crise sanitária provocada pela Covid-19, economistas de todos os matizes 
deveriam examinar de que maneira a política econômica poderia sobredeterminar as causas de morbimortalidade de uma sociedade.

Ora, se o quadro econômico antes da pandemia era preocupante, quando assistimos, no Brasil, à morte de mais de 158 mil pessoas e à existência de mais de 5,5 milhões de casos de Covid-19"1, não deixa de ser chocante constatar o subfinanciamento crônico do SUS, agravado pelo teto do gasto definido pela EC 95. Por isso, concordamos com a Petição Pública lançada pelo Conselho Nacional de Saúde (CNS) no dia 11 de agosto e apoiamos o piso emergencial de $\mathrm{R} \$ 168,7$ bilhões para o SUS em 2021, evitando a redução do seu orçamento em mais de $\mathrm{R} \$$ 35 bilhões $^{12}$.

Em pleno século XIX, Marx chamava a atenção para o fato de que a questão tributária é a mais velha forma de luta de classes. Nos dias atuais, o orçamento de guerra não pode se transformar em uma batalha do governo Bolsonaro e do poder econômico contra o fundo público, ao favorecer banqueiros, preservar a austeridade fiscal e secundarizar o SUS, colocando em risco a vida dos profissionais de saúde e da população brasileira.

Segundo Ocké-Reis ${ }^{6}$,

[...] para mitigar os efeitos das crises econômica e sanitária deveriam ser tomadas medidas para os mais ricos pagarem impostos. A fim de evitar o descontrole da inflação e o crescimento da dívida pública no período pós-pandemia, seu financiamento deveria ser feito por meio da taxação da riqueza. Neste grave momento da vida nacional, o bloco histórico sanitarista tem legitimidade para atuar perante a opinião pública junto com as frentes populares, os partidos de oposição, as centrais sindicais, os movimentos sociais, a juventude, os artistas e os intelectuais, convencendo tanto o centrismo a superar seu viés fiscalista, quanto a esquerda a superar seu divisionismo.

Ao assumir a defesa da vida como eixo da organização da política de saúde e da reforma pública do Estado, para Silva e Ocké-Reis ${ }^{4}$,

[...] a sociedade brasileira conta com a expectativa de que as forças políticas democráticas tenham a grandeza de construir um acordo suprapartidário, em que novos recursos destinados ao SUS seriam permanentes, em contraponto às consequências econômicas e sociais da pandemia, que não se limitarão a 2020.

\section{Colaborador}

Ocké-Reis CO (0000-0003-4666-7575)* é responsável pelo manuscrito. 


\section{Referências}

1. Ocké-Reis CO. Mudar a política econômica e fortalecer o SUS são medidas corretas para combater coronavírus [internet]. [acesso em 2020 set 7]. Disponível em: https://www.abrasco.org.br/site/ noticias/mudar-politica-economica-e-fortalecer-o-sus-sao-medidas-corretas-para-combater-coronavirus/45624/.

2. Ocké-Reis CO. Mudar a política econômica e fortalecer o SUS são medidas corretas para combater coronavírus [internet]. Abrasco. 2020 mar 12. [acesso em 2020 set 7]. Disponível em: https://www.abrasco.org. $\mathrm{br} /$ site/noticias/mudar-politica-economica-e-fortalecer-o-sus-sao-medidas-corretas-para-combater-coronavirus $/ 45624 /$.

3. Ocké-Reis CO. Salvar vidas? Fora Bolsonaro! [internet]. Jornal GGN 2020 maio 20 [acesso em 2020 jul 15]. Disponível em: https://jornalggn.com.br/a-grande-crise/salvar-vidas-fora-bolsonaro-por-carlos-ocke/.

4. Silva JAA, Ocké-Reis CO. A pandemia e o financiamento da saúde [internet]. Correio Braziliense. 2020 maio 20. [acesso em 200 set 7]. Disponível em: https://www.correiobraziliense.com.br/app/noticia/ opiniao/2020/05/20/internas_opiniao,856671/a-pandemia-e-o-financiamento-da-saude.shtml.

5. Costa AM, Rizzotto MLF, Lobato LVC. Na pandemia da Covid-19, o Brasil enxerga o SUS. Saúde debate. 2020; 44(125):289-296.

6. Ocké-Reis CO. Democracia brasileira sob fogo cruzado. Rev. Rosa [internet]. 2009 [acesso em 2020 set 7]; 1(3):1. Disponível em: http://revistarosa.com/1/ democracia-brasileira-sob-fogo-cruzado.
7. Moretti B, Ocké-Reis CO, Aragão E, et al. Dinheiro novo da saúde deve ser permanente [internet]. Jornal GGN. 2020 abr 10. [acesso em 2020 jul 15]. Disponível em: https://jornalggn.com.br/a-grande-crise/dinheiro-novo-da-saude-deve-ser-permanente/.

8. Stuckler D, Basu S. The body economic: why austerity kills. UK: Penguin; 2013.

9. Funcia FR, Benevides RPS, Ocké-Reis CO. Boletim COFIN/CNS[internet]. 2020 [acesso em 2020 set 7]. Disponível em: http://conselho.saude.gov.br/images/comissoes/cofin/boletim/Boletim_2020_0902_ T1_2_3_4_G1_ate_01_RB-FF-CO_revisado.pdf.

10. Moretti B, Ocké-Reis CO, Aragão E, et al. Mudar a política econômica e fortalecer o SUS para evitar o caos [internet]. Carta Capital. 2020 mar 29. [acesso em 2020 set 7]. Disponível em: https:// www.cartacapital.com.br/opiniao/mudar-a-politica-econo\%CC\%82mica-e-fortalecer-o-sus-para-evitar-o-caos/.

11. Conselho Nacional de Secretários de Saúde. Painel CONASS/COVID-19 [internet]. [acesso em 2020 out 27]. Disponível em: www.conass.org.br/painelconasscovid19/.

12. Moretti B, Ocké-Reis CO, Funcia FR. Por que o SUS não pode perder R $\$ 35$ bi em 2021, em meio à pandemia? [internet]. Brasil Debate. 2020 ago 18. [acesso em 2020 set 7]. Disponível em: https://brasildebate.com. br/por-que-o-sus-nao-pode-perder-r-35-bi-em-2021-em-meio-a-pandemia/.

Recebido em 15/07/2020

Aprovado em 21/09/2020

Conflito de interesses: inexistente

Suporte financeiro: não houve 